\title{
ROLE AND IMPORTANCE OF STHIRA BINDU (FIXED POINT) IN YOGA PHILOSOPHY
}

\author{
Kumar Subedi $^{1}$, Dinesh Panthi ${ }^{2}$, Kanhaiya Jha ${ }^{3}$ and Chet Raj Bhatta ${ }^{4}$ \\ ${ }^{1}$ Department of Mathematics, Mechi Multiple Campus, Tribhuvan University, Nepal \\ ${ }^{2}$ Department of Mathematics, Valmeeki Campus, Nepal Sanskrit University, Nepal \\ ${ }^{3}$ Department of Mathematics, School of Science, Kathmandu University, Nepal \\ ${ }^{4}$ Central Department of Mathematics, Tribhuvan University, Nepal
}
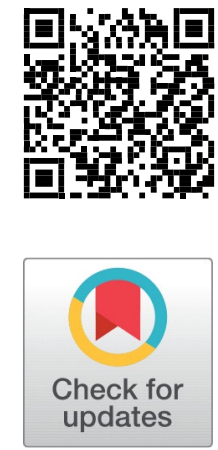

Received 6 June 2021

Accepted 18 June 2021

Published 30 June 2021

\section{Corresponding Author}

Kumar Subedi, subedikumar15@g mail.com

\section{DOI 10.29121/}

granthaalayah.v9.i6.2021.4022

Funding: This research received no specific grant from any funding agency in the public, commercial, or not-for-profit sectors.

Copyright: (C) 2021 The Author(s). This is an open access article distributed under the terms of the Creative Commons Attribution License, which permits unrestricted use, distribution, and reproduction in any medium, provided the original author and source are credited.

\section{ABSTRACT}

It is true that all living things and all the mechanisms of entire universe are guided by mathematical relations and results. The theory of fixed point is one of the most leading gears of modern mathematics and its results are the most generally useful in mathematics which gives the solution of nonlinear problems of various fields of modern subjects Dugundji and Granas (2003). Also, the human brain can perform the intellectual courses that still have not been performed by digital computers. It may therefore be seen that quantum mechanics is very much associated with the consciousness of mankind https://www.innerpeacefellowship.org/ (2021). Yoga is one of the few ways to understand the eventual reality mentioned in Vedanta, quantum physics and mathematics as well https://www.brettlarkin.com/ eight-limbs-of-yoga-patanjali (2021). This paper investigates the role and importance of fixed point in eastern philosophies especially with yoga along with meditation focusing that mathematics plays a significant role in yoga philosophy.

Keywords: Contraction, Convergence, Fixed Point, Meditation, NonLinear, Yoga

\section{INTRODUCTION}

The theory of fixed point is one of the most leading gears of modern mathematics like analysis and it is applicable in different fields. Let $\mathrm{T}$ is a self-mapping on a metric space $(X, d)$. Then, a point $\mathrm{X}$ in $\mathrm{X}$ is said to be fixed point of $\mathrm{T}$ if $\mathrm{T}(\mathrm{X})=$ $\mathrm{x}$; that is, a point which remains unchanged under a self-mapping is called a fixed point.This kind of result is the most generally useful in mathematics which gives the solution of non-linear problems of various fields of modern subjects Dugundji and Granas (2003). Also, the human brain can perform the intellectual courses thatstill 
have not been performed by digital computers. It may therefore be seen that quantum mechanics is very much associated with the consciousness of mankind https:// www.innerpeacefellowship.org/ (2021). Yoga is one of the few ways to understand the eventual reality mentioned in Vedanta, quantum physics and mathematics as well https://www.artofliving.org/us-en (2021). In 1922, S. Banach was the first to prove a fixed-point theorem for contraction mapping in metric space Banach (1922). Since then, a number of fixed-point theorems have been established by different authors and many generalizations of this notion have been established. Banach's fixed point theorem has been applied in many divisions of mathematics like as analysis, differential calculus, ODE and integral calculus, Image compression, Google's page rank algorithm, Newton-Raphson iteration, linear algebra, BVP etc.

Especially, in this article we discuss the role of fixed point in yoga and show the connection of fixed-point theory with yoga philosophy.

\section{EASTERN PHILOSOPHY}

That philosophy which follows omkar point is called Eastern philosophy. There are two types of eastern philosophies Ghimire (2077 B.S.), "Hemadri Mashik Patrika, Bhaktapur: Cherav Smriti Pratisthan, (Kartik-Paush)" (2077 B.S.):

- Haterodox (Nastik)

This philosophy says that no one can predict what will happen in the future, so what to do now is to do it instantly.

Heterodox Philosophies are further divided into four philosophies which are as follows:

1. Buddhism

2. Jainism

3. charvaka

4. Ajivika

The Jains initially worshiped idols (Murti) but later abandoned them. Ajivika tries to connect the two philosophies; heterodox and orthodox. Hence, these philosophies are mostly heterodox.

- Orthodox (Aastik)

This philosophy is based on the Veda Philosophy. It believes on future as well. Orthodox Philosophies are further divided into six philosophies (Shaddarshan)whichare as follows:

1. Nyaya

2. Samkhya 

3. Yoga
4. Mimamsha
5. Vedanta
6. Vaisheshika

Among these philosophies, we discuss here only about Yoga Philisophy along with Meditation.

\subsection{YOGA}

\subsubsection{BACKGROUND OF YOGA}

https: / www.brettlarkin.com/eight-limbs-of-yoga-patanjali (2021)

Yoga sutras of Patanjali yoga heard frequently are ancient practices. Actually, yoga is a science to change the some one's life making meaningful. One who practices yoga is called yogi. Now a days, three is a lot of demand of yoga in the world since it helps in physical exercise and mental refreshment as well.

Yoga comes from the sanskrit word yuj, meaning to unite and organize. It is the unification of body, mind and soul with a universal consciousness.

Yoga helps to get rid of distraction, disconnection from the usual consciousness so that it is regarded

One stanza of the path of Self Knowledge called path yoga included in Katha Upanishad of the 1st millennium BCE, in verses 2.6.6 through 2.6.13 is as follows Muller (1962).

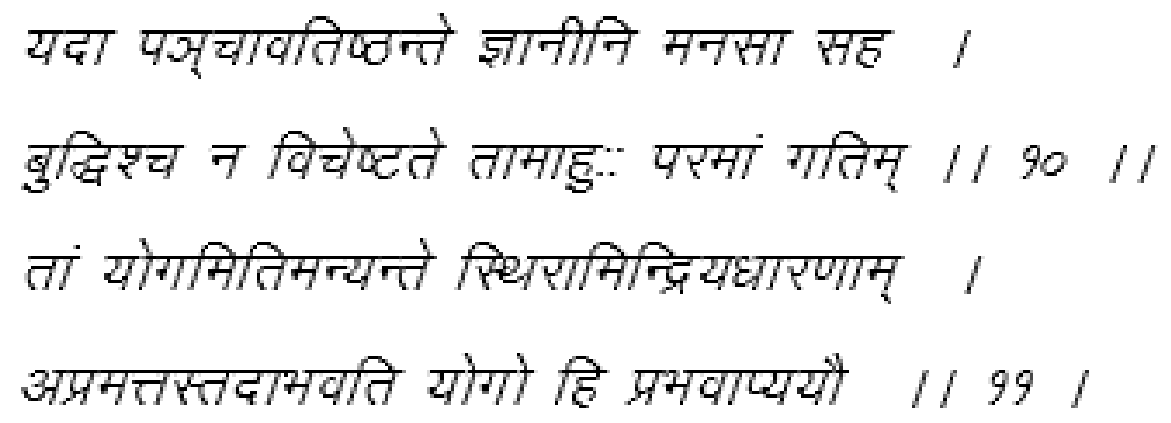

\subsubsection{EIGHT LIMBS OF YOGA http://www.b bc.com/earth/story (2021)}

Those beads called sutras interconnected each other are as follows:

1. Yama-It is also Self-control which help to create the peace and harmony among the world.

2. Niyama-It is also called observances which include personal conduct, rules and regulations

3. Asana-It is just the seat of yogi or the position of body during yoga 
4. Pranayama- It is the state of breath Control i.e., breathing exercises/inhale or exhale process.

5. Pratyahara - It is a state of interconnection of the external and internal practices of yoga to draw the internal sense.

6. Dharana - It is the state of focusing at a single point during the yoga practice.

7. Dhyana - It is the practice of dharana for a long time. It is also called the state of meditation.

8. Samadhi - It is ultimate state of yoga. Yogi gets blessed or enlightened at the end of this state.

The 8 limbs explained above are shown below in figure as well:

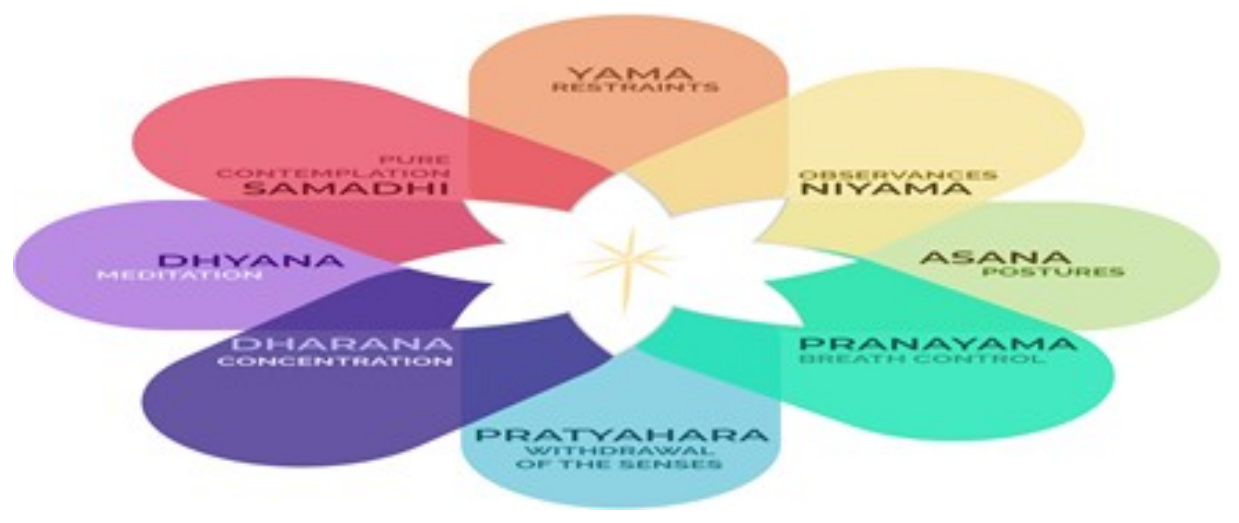

Figure 1 Eight Limbs of Patanjali Yoga [19]

Hence, the practice of restraint (yama), observances (niyama), posture(asana), breath control(pranayam), withdrawal(pratyahara) from the withdrawal senses, concentration (dharana), meditation (dhyan) and samadhi/bodhi(enlightenment) are the eight-fold path (limbs) of yoga meditation. As we discussed later on in a contraction theorem to get a fixed point, we can reach to enlightenment following these eight limbs.

\subsection{MEDITATION}

In 2073 B.S., Vishwanathan, I. published a book entitled " Hindu Dharma Ke Ho? and explained about meditation as follows Vishwanathan (2073 B.S.):

\subsubsection{WHAT IS MEDITATION?}

Meditation is the art of concentrating the mind. The word 'Meditation' is the consequent from the Latin word 'meditary' and it means to cure. Thus, mediation becomes the scientific treatment of all physical and mental patients and reached in easy solution. Meditation stabilizes (makes static) the mind. The power of mind is superior. you have to be able to win it by fighting with the mind for meditation. 
Even Lord Krishna was familiar with the power of the mind and telling to disappointed Arjun 'Hey' great/brave warrior; it is difficult to cease/control the mind. In every moment, it is unstill and moves around. Only from frequent and regular practice, the mind can be controlled. For meditation, the mind should be concentrated/controlled at first. Pranayam and Mantra yoga are the best way to control/concentrate the mind.

In the same way/Likewise, the scientists have divided the waves produced in the human brain into four parts as 'Alpha, Beta, Delta and Theta'. The fastest wave is the Beta. The most important method is the organic re-entering method. It is helping many people to relax/to be free from tension. Scientists have said that when a meditative yogi is in a state of meditating, he is being circulated through the waves 'Theta and Alpha' or 'Delta' or 'Beta'.

Hence, Meditation is a process of comforting, controlling \& concentrating the mind to feel internal pleasure and harmony.

\subsubsection{IMPORTANT SAYING/MAXIMS ABOUT MEDITATION}

In 2074 B.S., book of Osho, entitled "Bigyan Bhairab" was translated by Tulashi Bhattarai. Some important sayings are as follows Osho (2074):

There is no sleep now but external awakening (jagaran) is gone. The soul canbe enlightened if the realization can be remained in full understanding in the middle point. (p.143)

You exist in the same realization when there is a clear perception by a particular sense. (P.163)

You make such a feeling- "I am contemplating something, which is far from sight, cannot be apprehended (mentally seized) and grasped, which is the state of not being-I"(p.-217).

Every object is seen through knowledge, it is revealed (enlightened) in the realm (domain) of the soul through knowledge- understand that one as the 'knower' and the 'knowable'. Feel yourself spreading/pervading in all directions. (P. 47)

The properties of objects and subjects are equal for the wise and the ignorant. The greatness of the sage (gyani) is to remain steadfast(static) in the spiritual theme. Sage does not frighten and confuse with anything. (P.249)

\subsubsection{THE SCIENCE OF MEDITATION Ananda Arun (2010)}

In 2010, Ananda Arun, S. had published a book entitled "Santa Darshan" and explained about the science of meditation as follows Ananda Arun (2010):

Meditation can't be confined/restricted to any religion. Meditation is pure science and the science of consciousness. Meditation is found to be embraced by all religions in one form or another.

Chanting mantra, Yoga, Pranayam, Dharana, Namaz, sufi, Darmesh Nritya, Tratak, Tantra, Bipasyana, Tai-chi, Latihan- all these are the forms of meditation which bring 
us to a pure state of consciousness.

The flow of infinite emotion impulses our thought, subject desire and affects our consciousness. Reminiscences frequently lay in mind/heart and optimism run smoothly. Our heart or thoughts run even in a deep sleep. Meditation is in its contrary where our thoughts remain silent. In meditation, we keep in full silence. Meditation makes mind/heart/thought peaceful and arrives in the state of pure consciousness. Meditation is the state of blissfulness (Param Ananda). This brings us to unstill mind to the state of still consciousness or soul.

Thoughtless consciousness is our natural state but we have lost it by yearning (Utkantha) fallen from the paradise- "swargabat chyut bhayeko"- This is the meaning of the word of the Bible. It is possible to re-enter that paradise(heaven) through meditation.

\subsubsection{BENEFITS OF MEDITATION https://www.innerpeacefellowship.org/ (2021)}

There are a lot of benefits of meditation. Some general benefits are as follows $h t t p s: / /$ www.innerpeacefellowship.org/(2021):

1. Improved memory and concentration.

2. Increased confidence and self-esteem.

3. Improved sense of self-worth.

4. A more positive body image.

5. Greater creativity.

6. Feelings of calmness and inner peace.

7. Improved behavioral profile

Other important benefits (Backed by Science) are as follows https://examstudyexpert .com/benefits-of-meditation-for-students/ (2021):

1. Improves attention

2. Fewer distractions, better focus

3. Concentration for longer time

4. Lower's stress levels

5. Copes better withstress

6. Helps with exam nerves

7. Improves self-esteem

8. Greater well-being and happiness

9. Better resilience

10. Improves social skills

11. Greater sympathy and compassion 
12. Improves working memory

13. Improves response inhibition

14. Metacognition (learning/knowing about own memory)

15. Might even change the very fabric of a student's brain

16. Improves sleep quality

17. Relieve from anxiety

18. Helps alleviate depression

19. Even improvements in physical health

20. Improves knowledge retention during lectures

21. Improved performance with learning disabilities

\subsection{CONCENTRATED MIND AND ITS POWER}

In 2073(B.S.), Swami Khaptad Baba has written a book entitled "Science of Thought (Bichar Bigyan). He has explained about the Concentrated Mind and its Power as follows Khaptad Baba (2073 B.S.):

In the minds of people, all new ideas are generated. In human mind/heart, new thoughts arise continuously, one after another. According to anthropologists, the man who breathes, in each these breaths, new ideas arise. Like shape shrapnel in a gun dropping a bullet can have dire consequences.

Large and impossible works can be obtained by collecting and flowing atoms of air, water, also steam, electricity, fire etc.

In his way, when the thoughts are also fixed on the same object by meditation then wonderful power is generated and the road seeker achieves the object, she/he imagined.

Chhandogyaupanishad says:

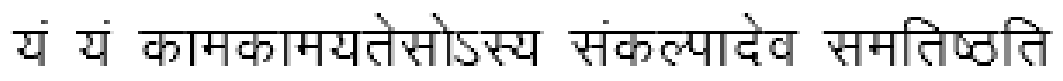

Meaning: A man with a concentrated mind desires something that is obtained only by resolution/determination.

\subsection{STHIRA BINDU (FIXED POINT) SADHANA}

\section{https://www.sathyasai.org (2021)}

Sadhana is the Sanskrit word for spiritual practice or spiritual discipline. It is useful to achieve the goal of our life according to Bhagawan Sri Sathya Sai Baba. "How do you do sadhana? By making your outlook pure. It is 'taking out' from within you what is bad and evil, your negative traits. It is also 'recognizing and bettering' what is good and godly in you, your positive traits" (SanathanaSarathi,1996). This universal process purifies your consciousness. Sadhana purifies your mind and heart. 
Sathya Sai Baba revealed that "every religion has, as its technique, this transformation, this cleansing process" (SSS 8.35). This process incorporates many spiritual practices. https://www.sathyasai.org (2021).

Fixed point is important for sadhana since during sadhana, for the first time, everybody should concentrate to a fixed-point regarding rules/regulations/devotion/discipline/conviction mentally, spiritually and physically as well so that s/he can concentrate towards the pace of sadhana and achieve the goal of enlightenment of life.

Likely, fixed point plays a vital role during Tratak Meditation and Vindu - Nada Dhyan (Meditation) which will clearly be justified from the following discussion about them.

\subsection{TRATAK (त्राटक) MEDITAITON AND STHIRA BINDU (FIXED POINT)}

https://litairian.com/tratak-meditation-benefits-powers-method/(2021) https:// www.indiatvnews.com/health/tratak-kriya-for-concentration (2021)

Tratak Meditation is an ancient form of yogic meditation. It is a very simple yet very powerful technique of meditation to achieve Divine Hidden Powers. Tratak is a meditation, where a person can sit, stare(watch) and focus continuously at a single point.

There are many different types of Tratak based on the object used for Tratak. Here are the details of some Tratakas.

1. Bindu Tratak: focus on a Single Black Dot.

2. Murti Tratak: focus on an Idol.

3. VartulTratak: focus on a Circle.

4. ValayTratak: focus on a SpiralRing.

5. Jyoti Tratak: focus on a Flame of a Lamp or a Candle.

6. Surya Tratak: focus on Early Sunrise or just before Sunset. This is done in less than 5 minutes with expert guidance only.

7. TrinetraTratak: focus on one's own Third Eye.

\section{Stages of Tratak Meditation}

There are three main stages of Tratak which are as follows:

1. BahirangaTratak or External Tratak: It involves continuous gazing of a single object or points to the extent that you may shed tears from your eyes.

2. AntarangaTratak or Internal Tratak1: If you still continue to gaze at the object or the point, when you close your eyes, you can still visualize or see the impression of the same object or the point in front of you.

3. AntarangaTratak or Internal Tratak 2: When you focus on any part of your inner body like your third eye, your heart chakra, etc. is called Internal Tratak. 


\section{Benefits of Tratak Meditation}

Tratak activates your inner potential. The mind is always wavering and oscillating in multiple thoughts. When you continuously gaze at one object, the brain gets habituated to that object. The alpha brain waves increases and connection to the external world reduces. There comes a point, where a mind is completely shut to an external environment and one becomes blank to all the thoughts. One may experience freedom from both time and space.

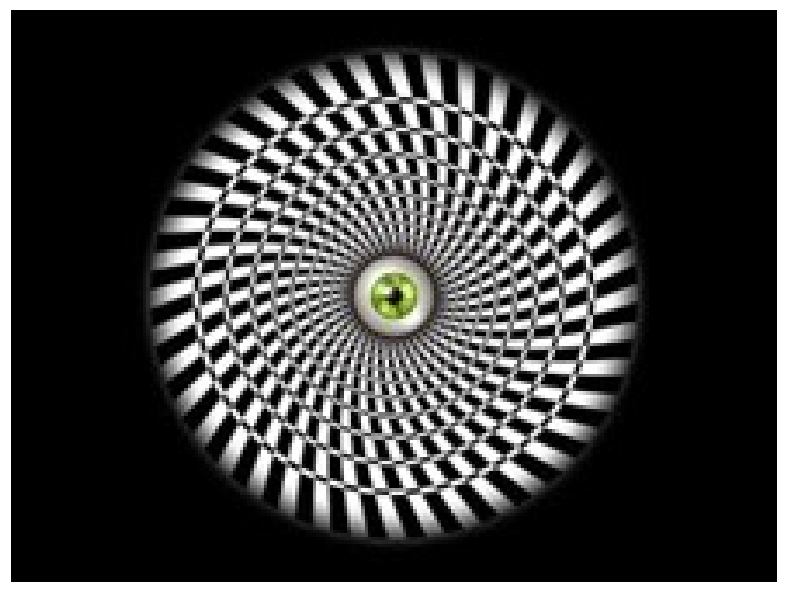

Figure 2 Sthira Bindu (Fixed Point) in Tratak Meditation

According to Swami Ramdeva, the tratak kriya is performed using points, stars, sun, moon, lamp, candle etc. In the beginning, you can use a lamp.

Obviously, tratak meditation is a process of focusing the mind in a single point i.e., fixed point.

\subsection{BINDU AND CONCENTRATION OF MIND $h t t p s: / / w w w . d a h n y o g a{ }^{\prime}$ net/ techniques/bindu-and-concentration-of-mind.html (2021)}

A Sanskrit word Bindu (बिंदु) means "point", "drop" or "dot" and from viewpoint $f$ Bindu Yoga, it means termination or nullification of spiritual variations. The mind is sluggish, interested and entirely one-point. It is transparent - a perfect mirror of clean perception. In the renowned Yoga Sutras by Patanjali, it declares: "Stopping the outline of perception is yoga".

Mind concentration is carried about by Raja Yoga technology. The point (Bindu) is not stated in the whole scripture, but they are actually saying the similar entity. The concentration of the perfect mind indicates that the point (Bindu) is consciousness. Point (Bindu) penetrating, as in Kriya Yoga, indicates that the mind has the right concentration. The point (Bindu) also indicates the complete termination of all mental ups and downs; At this stage, the path of yoga is converted into the empirical knowledge of yoga. 
Thus, breathing control, meditation of the brain and point are closely related. After the mind is focused on the point, it goes from a finite to an infinite. An area of the brain goes out. That is why concentration in the mind is the necessary for all yoga performs and mystical life in general. Penetrating the point, this person goes into the realm of pure consciousness, of nada (null) time - endless.

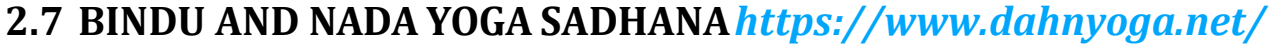 techniques/bindu-and-nada-yoga-sadhana.html (2021)}

According to ancient Indian philosophy, consciousness manifests itself through nada (subtle vibrations). There are three notable concepts: kala, Bindu and nada. Bindu is an inland theory mentioned under the title 'Evolutionary Effects'. The point (Bindu) is the point through which consciousness manifests itself in the fashioned creation. Nada is the flow of consciousness in the object of conception through the point. This process can be compared to a funnel: point (Bindu) and kala bring consciousness into a concentrated flow, and nada is the medium through which consciousness continues in a delimited orbit. When Nada goes up, then conception occurs. It is represented by the path of instinct (Pravriti Marga) and is called expression or physical development. Nada is considered as the connection between untainted consciousness and all fashioned matters. It can also be used to move in the reverse course - the path of retirement (Nivriti Marga). That is, Nada seekers can use them to merge with the source of consciousness, the Sahasrara, the untainted consciousness. For this, Nada has to go up from the point.

Thus, Nada Yoga is a way of taking back the path of Nada which was the innovative means for personal development and existence. With detailed practice, a person's perception becomes more sophisticated and subtle. Ultimately, one's perception of the sensitive nada becomes so delicate that one will be cognizant of theBindu. This consciousness is the gateway to purification. This is the heart of Nada Yoga Sadhana.
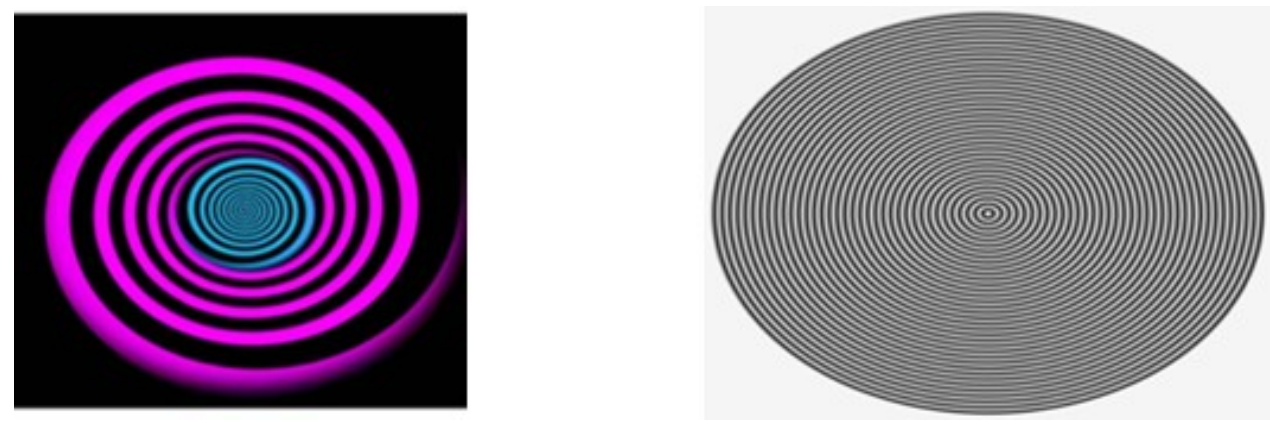

Figure 3 Sthira Bindu (Fixed Point) at the center https://www.quora.com/What-are-some-tips-and -tricks-to-increase-concentration-power (2021) , https://www.vippng.com/maxp/Jwbmbi/ (2021)

Concentration is the well achieved state of mind when all the sense organs are in perfect harmony. Our life becomes so busy that we fail to concentrate on our work/- 
daily activities.

By name also it is Bindu (point) itself and regarding nature also, Bindu Yoga is the process of cessation of all mental fluctuations and concentrate the human mind into a fixed which is clarified with the above discussion and images included with.

\subsection{AUMKAR BINDU https://www.swamij,com/bindu.htm (2021)}

Each stream of AUM guide to the convergence called Bindu:

The convergence point guided by the three streams of Yoga, Vedanta and Tantra is called Bindu.

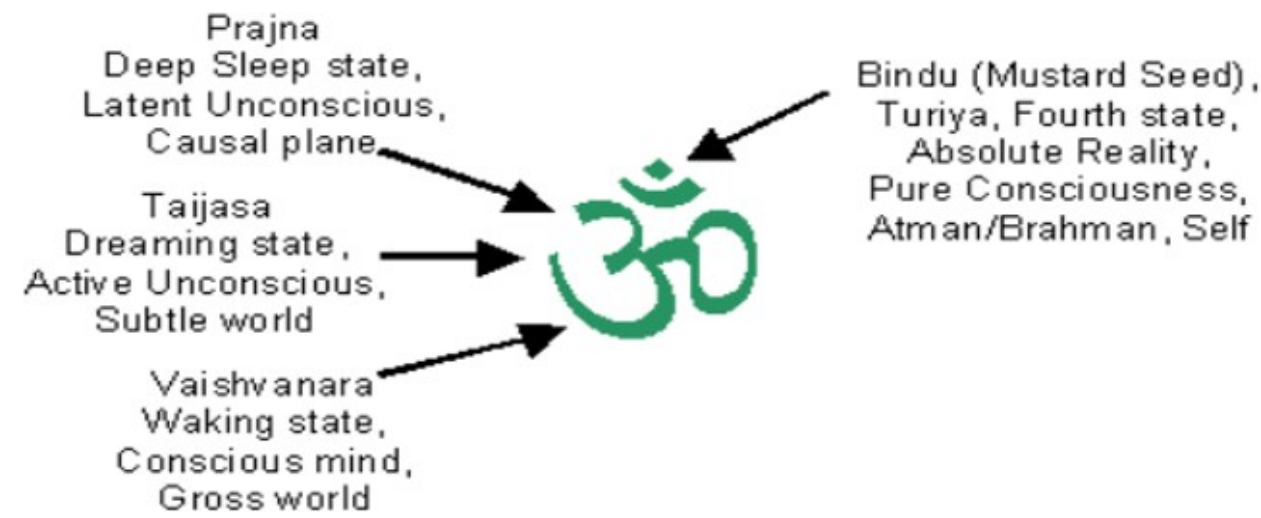

The lowermost curve signifies the large, Aware and Mobile state level and it is named as Vaishvanara. The curve at the center signifies the Delicate, Insensible and Imagining level, named as Taijasa. The curve at the upper part signifies the Causal, Subconscious and Deep Sleep level, named Prajna.The dot, point or Bindu signifies the absolute realization which incorporates, infuses and named as Turiya. The arc just below the dot signifies the distinctiveness of Turiya https://www.learnkathakonline.com (2021)

Actually, the dot point can be regarded as the fixed point which is the state of full consciousness of anyone.

\subsection{PASHUPATI TATWA (ELEMENT) AND BINDU (POINT) SADHANA} In 2073 (B.S.), Dahal, B. had written a book entitled "Pashupatima Sat Din" and included some important literature about fixed point as mentioned below Dahal (2073 B.S.):

सच्चिदानन्दविभवात् सकलात् परमेश्वरात ।

आसीच्शक्तिस्ततो नादो नादाद् विन्दु समुद्धव: // शारदा तिलक १७६ 
Sound (Nad) arises from the half-power of sachchidananda Brahman. The point emerges from the sound (Nad).

Such a point tends to be an integral power element in itself. There are Three functions of Bindhu Sadhana.

1. Bidhisodhan Kriya: Only by purifying the vision, one can enter the path (Bidhimarga

2. Upliftment (Bindu Utthan Kriya: Practice is required for the transformation of function(kriya

3. Bindhu Dharana Kriya: It enhances the ability to evaluate events in the world and their effects. It is a dimension of celebration and joy of gaining new experience and realization.

Bindu Mathan gives both the ultimate happiness and salvation (rescue.) It acts as the ultimate medicine for the purpose of strengthening and enriching the internal organs of the body and the system. As long as the point in the body remains stable (static), there is no fear of death. Destruction is of course possible after the point has collapsed. The seeker who wants to avoid the fear of death should pay attention to the protection of the point. Several ways are described in the scriptures(sastra) to stabilize (make static) the point.

$$
\begin{aligned}
& \text { विन्दुसंरक्षणस्यानो विधि: सम्पाप्यते } S \text { पि च } \\
& \text { नासमूले च मध्ये च ध्यानाद् विन्दु: स्थिरोभवेत् // ३२२ }
\end{aligned}
$$

Protecting the base (core part) and the middle part of the nose between the two eyebrows, the point can be stabilized by meditation.

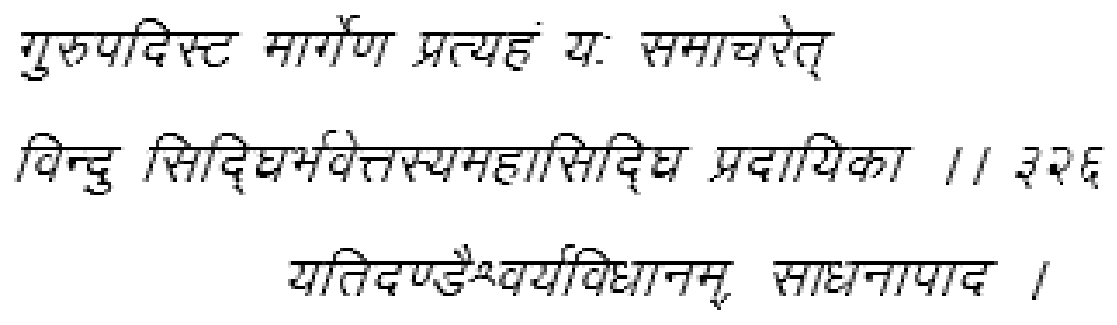

With the help of the Guru's sermon (lecture), the seeker succeeds in Bindu siddhi (achieving the point) by advancing the sadhana/meditation every day and eventually achieves competency.

In this philosophy we can directly get the core literature of fixed point. 


\subsection{MEDITATION AND YOGA $h t t p: / / w w w$.raeindigo.com/ importance-meditation-yoga-practice-2/ (2021), https://kfoundation.org/meditation (2021)}

Meditation was regarded as the most essential part of the ancient yoga and yoga practice. Also, in recent time, meditation has become an inseparable part of yoga since initially it concentrates to the state of seat and then breathing air which are absolutely important for yoga.

Meditation can decrease anxiety, aching, worry, cardiac diseases and sleeplessness. Then it improves Positivity, creativity, connection changing the brain and improves one's wellbeing. Yoga also plays the same role following the most of the procedures of meditation. So, there is keen relationship between yoga and meditation.

Hence, meditation is a very sensitive profession. Mediation not only means concentration of mind but also a vital arrangement of devotion. Meditation provides

solution in the mind since it helps on illumination of unwanted thought, forming silence of the brain, creating harmony on mind, concentrate and enlightenment it that the similar flow proceeds forward in Yoga. The nature of the mind is to wander away. Meditation makes to concentrate the mind to a fixed point so that to provide the real solution (peace and happiness) of life. The same role is played by yoga but it should follow fundamental rules of meditation. Therefore, it will be more comfortable and fruitful it yoga and meditation are carried out simultaneously.

Now, at first, the fixed-point theorems are included as follows:

\section{SOME FIXED POINT AND RELATED THEOREMS}

First of all, we start from the most well-known fixed-point theory and then other relevant theorems.

\subsection{BANACH CONTRACTION PRINCIPLE Bartle and Sherbort (2000)}

Let $(X, d)$ be a complete metric space and let $f: X \rightarrow X$ be a contraction function. Then $\mathrm{f}$ has a unique fixed point or $\mathrm{f}(\mathrm{x})=\mathrm{x}$ has a fixed point.

\subsection{BOLZANO THEOREM Apostal (1842)}

Leta continuous function defined on the closed interval [c, d] be f such that $f(c)$ and $f(d)$ have opposite signs i.e., $f(c) . f(d)<0$. Then there exists at leastone pointe in the open interval $(c, d)$ such that $f(e)=0$.

\subsection{FIXED POINT ITERATION METHOD Balagurusamy (2018)}

It is a method which helps to Solve Non-linear Equation. The procedure is as follows:

Le a function be $\mathrm{g}(\mathrm{x})=0$......(i) and let us manipulate $\mathrm{x}$ as

$$
\mathrm{x}=\mathrm{h}(\mathrm{x}) \ldots . . .(\mathrm{ii}) \text {. }
$$


Equation (i) and (ii) are equivalent and therefore a root of equation (ii) is also a root of equation (i). The root of equation (ii) is given by the solution of the curve $y=$ $\mathrm{x}$ and $\mathrm{y}=\mathrm{h}(\mathrm{x})$. This intersection point is known as the fixed point ofg(x).

The above transformation can be obtained either by algebraic manipulation of the given equation or by addition of $x$ to each side of the equation.

For example: let us express $x^{2}+x-2=0$ as

$\mathrm{x}=2-\mathrm{x}^{2}$ and further adding $\mathrm{x}$ on both sides, $\mathrm{x}=\mathrm{x}^{2}+\mathrm{x}-2+\mathrm{x}$ then it reduces to $\mathrm{x}$ $=x^{2}+2 x-2$

Adding $\mathrm{x}$ to both sides is normally done in situations where the original equation is not amenable (agreeable) to algebraic manipulations. For example

$\tan \mathrm{x}=0$ would be put into the form of equation (ii) by adding $\mathrm{x}$ to both sides.

That is $\mathrm{x}=\tan \mathrm{x}+\mathrm{x}$.

The equation $\mathrm{x}=\mathrm{g}(\mathrm{x})$ is known as the fixed-point equation. It provides a convenient form for predicting the value of $\mathrm{x}$ as a function of $\mathrm{x}$. If $\mathrm{x}_{0}$ is the initial guess to a root then the next estimate is given by

$\mathrm{x}_{1}=\mathrm{h}\left(\mathrm{x}_{0}\right)$

Further approximation is given by $\mathrm{x}_{2}=\mathrm{h}\left(\mathrm{x}_{1}\right)$

This iteration process can be expressed in general form as

$\mathrm{x}_{i+1}=\mathrm{h}\left(\mathrm{x}_{i}\right), \mathrm{i}=0,1,2,3, \ldots \ldots$ (iii)

which is the formula of fixed-point iteration.

This method of solution is known as the method of consecutive approximations or method of direct substitution. The algorithm is very simple. The iteration process would be terminated when two successive approximations agree within some specified error.

\subsection{NUMERICAL PROBLEM Balagurusamy (2018)}

Find the solution of the equation $\mathrm{x}^{2}+\mathrm{x}-2=0$ by fixed point method.

Solution: The equation can be expressed as $\mathrm{x}=2-\mathrm{x}^{2}$

Let us start with an initial value of $\mathrm{x}_{0}=0$

$\mathrm{x}_{1}=2-0^{2}=2, \mathrm{x}_{2}=2-2^{2}=-2, \mathrm{x}_{3}=2-(-2)^{2}=-2$

Since, $x_{3}-x_{2}=0,-2$ is one of the roots of the equation.

Again, let us assume that $\mathrm{x}_{0}=1$. Then

$\mathrm{x}_{1}=2-1^{2}=1, \mathrm{x}_{2}=2-1^{2}=1$

Since, $x_{2}-x_{1}=0,1$ is another root of the equation.

Let us assume that $\mathrm{x}_{0}=-1$. Then

$\mathrm{x}_{1}=2-(-1)^{2}=1, \mathrm{x}_{2}=2-1^{2}=1$, again, another root is 1 .

\subsection{NUMERICAL PROBLEM Balagurusamy (2018)}

Evaluate the square root of 5 by fixed point iteration algorithm.

Solution: Let us change the given equation as $\mathrm{x}=\frac{5}{x}$ and assume $\mathrm{x}_{0}=0$. Then $\mathrm{x}_{1}=5, \mathrm{x}_{2}=1, \mathrm{x}_{3}=5, \mathrm{x}_{4}=1$ 
This process does not converge to the solution. This type of divergence is known as oscillatory divergence.

Let us consider another form of $\mathrm{g}(\mathrm{x})$ as shown as below:

$\mathrm{x}=\mathrm{x}^{2}+\mathrm{x}-5$ and assume $\mathrm{x}_{0}=0$. Then $\mathrm{x}_{1}=-5, \mathrm{x}_{2}=15, \mathrm{x}_{3}=235, \mathrm{x}_{4}=55455$

Again, it does not converge. Rather, it diverges rapidly. This type of divergence is known as monotone divergence.

Let us try a third form of $\mathrm{g}(\mathrm{x})$.

$$
2 \mathrm{x}=\frac{5}{x}+\mathrm{x} \Rightarrow \mathrm{x}=\frac{\frac{5}{x}+x}{2}
$$

and assume $\mathrm{x}_{0}=1$. Then, $\mathrm{x}_{1}=3, \mathrm{x}_{2}=2.3333, \mathrm{x}_{3}=2.2381, \mathrm{x}_{4}=2.2361, \mathrm{x}_{5}=$ 2.2361. This time, the process converges rapidly to the solution. The square root of 5 is 2.2361 .

From above example, we can see that the convergence of solution is not convergence in all form.

It will converge only in the form of $x=g(x)$ when the absolute value of the slope of $\mathrm{y}=\mathrm{g}(\mathrm{x})$ is less than the slope of $\mathrm{y}=\mathrm{x}$. Since, the slope of $\mathrm{y}=\mathrm{x}$ is 1 , necessary condition for convergence is $\mathrm{g}^{\prime}(\mathrm{x})<1$.

It is obvious that human brain may not always proceed forward linearly. As we are human beings, our everyday activities and environment may not be always linear (favorable). So far, we concern and hear the news that everybody should face lots of problems daily. There may exist a lot of non-linear problems. However, people should survive struggling against them. During those moments there may arise many solutions but all of them may not be appropriate. Selection of the best solution is very difficult task. Though, meditation is the best way which will make us able to tolerate and choose the best solution with peaceful mind through elimination of unnecessary thought, creating quiet and peaceful environment and then iteration to concentration to get the best solution through the enlightenment of mind.

We saw in above non-linear mathematical problem that solving and getting the solution (i.e., fixed point) of any non-linear problem, certain conditions and precautions should be accounted on. Similarly, Yoga-Meditation is the best way to provide the solution of non-liner functions and problems in everyday life as we mentioned above literature in detail.

\subsection{CAUCHY AND CONVERGENT SEQUENCE}

\subsubsection{CAUCHY SEQUENCE Shrestha and Pahari (2014)}

A Sequence $\left\{\mathrm{X}_{n}\right\}$ real numbers is regarded as a Cauchy sequence if for all small positive number $\epsilon>0 \exists$ a positive integer $\mathrm{N}$ such that

$$
\mathrm{d}\left(\mathrm{x}_{\mathrm{n}}, \mathrm{x}_{\mathrm{m}}\right)<\in \forall \mathrm{n}, \mathrm{m} \geq \mathrm{N}
$$




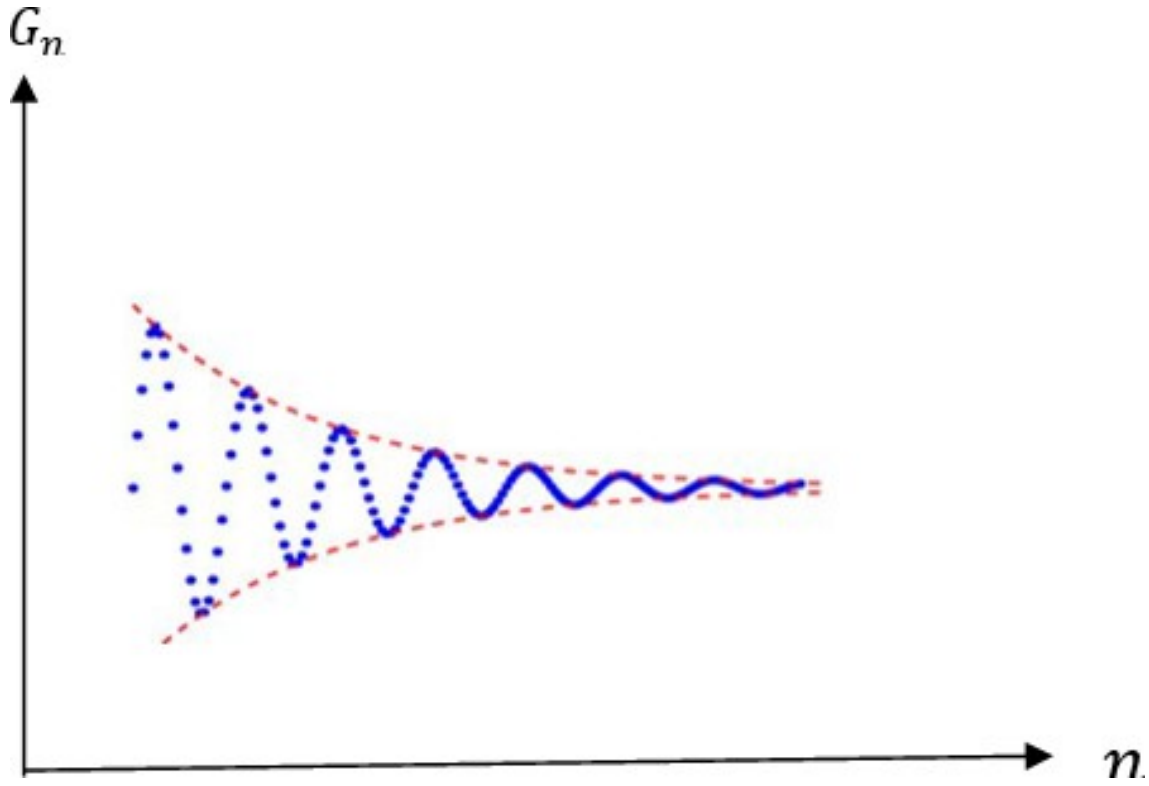

\subsubsection{CONVERGENT SEQUENCE Shrestha and Pahari (2014)}

An infinite sequence $\left\{x_{n}\right\}$ of real numbers $R$ is said to converge to a point $x \in R$ if $\forall \in>0$, there $\exists$ an integer $N$ such that $d\left(x_{n}, x\right)=\left|x_{n}-x\right|<\in$ whenever $n \geq N$, where, $\mathrm{x}$ is the limit of $\left\{x_{n}\right\}$. i.e. $x_{n} \rightarrow x \Rightarrow \lim _{n \rightarrow \infty} x_{n}=x$

For Example: A sequence

$$
\left\{x_{n}\right\}=\left\{\frac{1}{\mathrm{n}}, \mathrm{n} \in \mathbb{N}\right\}=\left\{1, \frac{1}{2}, \frac{1}{3}, \ldots\right\}
$$

converges to 0 .

Similarly, we can take the following example and discuss as follows:

\subsubsection{EXAMPLE}

Suppose a young groom is interested to marry with a bride. He starts shorting the probable brides. Ultimately reaches to the decision.

let, the sequences of brides (girls) be $\left(G_{n}\right)=\left(G_{1}, G_{2}, G_{3} \ldots \ldots \ldots\right)$. It can be justified with the following example.

\subsubsection{SOLUTION OF A REAL VALUED NON-LINEAR FUNCTION DEFINED ON AN INTERVAL Bajracharya et al. (2014)}

Using Newton-Raphson's Method compute a root of $x^{3}-x-4=0$ between 1 and 2 to three places of decimal by Newton-Raphson's Method. 
Let, $f(x)=x^{3}-x-4$. Then, $f^{\prime}(x)=3 x^{2}-1$. Here, $f(1)=-4, f(2)=2$

Since, $f(1) . f(2)<0$, by Bolzano theorem, the roots of given equation lies in between $(1,2)$.

Using the formula,

$$
x_{n+1}=x_{n}-\frac{f\left(x_{n}\right)}{f^{\prime}(x)}
$$

let $x_{0}=2$ be initial guess. Then

$$
\begin{aligned}
& x_{1}=x_{0}-\frac{f\left(x_{0}\right)}{f^{\prime}\left(x_{0}\right)}=2-\frac{(2)^{3}-2-4}{3 .(2)^{2}-1}=1.81819 \\
& x_{1}=x_{0}-\frac{f\left(x_{0}\right)}{f^{\prime}\left(x_{0}\right)}=1.81819-\frac{(1.81818)^{3}-1.81819-4}{3 \cdot(1.81819)^{2}-1}=1.79662 \\
& x_{2}=x_{1}-\frac{f\left(x_{1}\right)}{f^{\prime}\left(x_{1}\right)}=1.79662-\frac{(1.79662)^{3}-1.79662-4}{3 .(1.79662)^{2}-1}=1.79633
\end{aligned}
$$

Comparing the values of $\mathrm{x}_{2}$ and $\mathrm{x}_{3}$, we find that the digits in the first three places of decimal are the same. Hence, we can take this as the approximate value of the root to three places of decimal. In other words, the required approximate solution is 1.796.

We, see that the sequence of solutions is $\left\{\mathrm{x}_{n}, n \in N\right\}=\{1.81819,1.79662$, $1.79633, \ldots \ldots \ldots\}$. Here, we got the solution (i.e., fixed point) starting with a guess solution. We executed the first guess and got next value. Again, we executed second value and got third value. We continued the process until we get the solution or point of concentration that we regard as the fixed point.

Similarly, when someone has any problem then s/he starts thinking the probable solution. Continuously until she gets the exact solution regarded as the point of concentration or saturation called fixed point. Panthi (2017).

The nature of the meditation is to focus the feelings into a single point which is same in Cauchy sequence advancements for the convergence. So, Cauchy sequence is helpful for making decision inevery day life Panthi (2017). Similarly, it is similar to the process of iteration to the concentration used in Newton-Raphson's Method for the solution of non-linear solution.

\section{CONCLUSION}

The seven functions of the mind are Consciousness, Thoughts, Emotions, Perceptions, Memory, Intelligence and Judgment.

The practice of restraint (yama), observances (niyama), posture(asana), breath control (pranayam), withdrawal(pratyahara) from the withdrawal senses, concentration (dharana), meditation (dhyana) and Samadhi /bodhi (enlightenment) are the 
eight-fold path (limbs) of yoga meditation. As we discussed in above a contraction theorem to get a fixed point, we can reach to enlightenment following these eight limbs.

Any non-linear problem can be solved using the fixed-point theory, Bolzano theorem, Fixed Point Iteration Method and Newton-Raphson's Method etc. as mentioned above to solve the problems by iteration and reach to the point of concentration i.e., approximate solution as like as the practice of the eight limbs of Patanjali yoga.

Also, by meditation one can reach to the fixed point through concentration controlling movement, sense organs, breathing and ultimately self-control.

Similarly, by Omkar Chanting, everybody can be enlightened with concentration following iteratively the different stages of meditation.

Also, there is clearly discussed about the fixed-point concentration in PASHUPATIKA SAT DIN. From all of the above arguments we can conclude that there is an association of fixed-point theory with yoga meditation.

Likely, nature of the meditation is to concentrate the thoughts into a single point. Cauchy sequence is helpful in decision making in everyday life since the process of concentrating the mind is exactly the same as the Cauchy sequence progresses for the convergence. So, fixed point theory has an application in yoga philosophy.

\section{REFERENCES}

Ananda Arun, S. (2010). Santa Darshan. In and others (Ed.), . Kathmandu; Nagarjun, Osho Tapoban.

Apostal, T. M. (1842). Mathematical Analysis, (2nd ed.). India: Narosa Publishing House.. Bajracharya, D. R., et al. (2014). Basic Mathematics. Kathmandu: Sukunda Publication.

Balagurusamy, E. (2018). Numerical Methods, (46th edition). India: McGraw Hill Education Private Limited., 160-163.

Banach, S. (1922). Sur les opérations dans les ensembles abstraits et leur application aux équations intégrales. Fundamenta Mathematicae, 3(7), 133-181. Retrieved from https://dx.doi.org/10.4064/fm-3-1-133-181

Bartle, R. S., \& Sherbort, D. (2000). Introduction to Real Analysis. New York: Wiley. Brown, R. F. (1988). Fixed Point Theory and Its Applications, ISBN 0-8218-5080-6. Dahal, B. (2073 B.S.). Pashupatima Sat Din, Kathmandu: Mandap Books., 96-97. Dugundji, J., \& Granas, A. (2003). Fixed Point Theory, Springer-Verlag, ISBN 0-387-00173-5. Ghimire, I. P. (2077 B.S.). Vaidik Darshan Samkshipta Parichaya. Cherav Smriti Pratisthan. Hemadri Mashik Patrika, Bhaktapur: Cherav Smriti Pratisthan, (Kartik-Paush), (2077 B.S.). Khaptad Baba, S. (2073 B.S.). Science of Thought (Bichar Bigyan). Kathmandu: Khaptad Ashram Prakashan samiti., 27.

Muller, M. (1962). Katha Upanishad, Part-II, New York: Dover Publications, 22. ISBN 978-0486-20993-7.

Osho, S. (2074). Bigyan Bhairav Tantra. Kathmandu: Madhuvan Prakashan., 143-149. Panthi, D. (2017). A spiritual fixed-point theorem. International Journal of Statistics and Applied Mathematics, 2(5), 2456-1452.

Shrestha, R. M., \& Pahari, N. P. (2014). Fundamentals of Mathematical Analysis. Kathmandu: Sukunda Publication. 
Vishwanathan, I. (2073 B.S.). Hindu Dharma Ke Ho? Kathmandu: Brother Books Publication Pvt (Ltd.)., 123-125.

(2021). Retrieved from https://examstudyexpert.com/benefits-of-meditation-for -students/

(2021). Retrieved from https://kfoundation.org/meditation

(2021). Retrieved from https://litairian.com/tratak-meditation-benefits-powers-method/

(2021). Retrieved from https://www.artofliving.org/us-en

(2021). Retrieved from https://www.brettlarkin.com/eight-limbs-of-yoga-patanjali

(2021). Retrieved from https://www.dahnyoga.net/techniques/bindu-and-concentration -of-mind.html

(2021). Retrieved from https://www.dahnyoga.net/techniques/bindu-and-nada-yoga -sadhana.html

(2021). Retrieved from https://www.indiatvnews.com/health/tratak-kriya-for -concentration

(2021). Retrieved from https://www.innerpeacefellowship.org/

(2021). Retrieved from https://www.learnkathakonline.com

(2021). Retrieved from https://www.quora.com/What-are-some-tips-and-tricks-to -increase-concentration-power

(2021). Retrieved from https://www.sathyasai.org

(2021). Retrieved from https://www.swamij.com/bindu.htm

(2021). Retrieved from https://www.vippng.com/maxp/Jwbmbi/

(2021). Retrieved from http://www.bbc.com/earth/story

(2021). Retrieved from http://www.raeindigo.com/importance-meditation-yoga-practice $-2 /$ 